EUROPEAN ORGANIZATION FOR NUCLEAR RESEARCH

CERN LIBRARIES, GENEVA
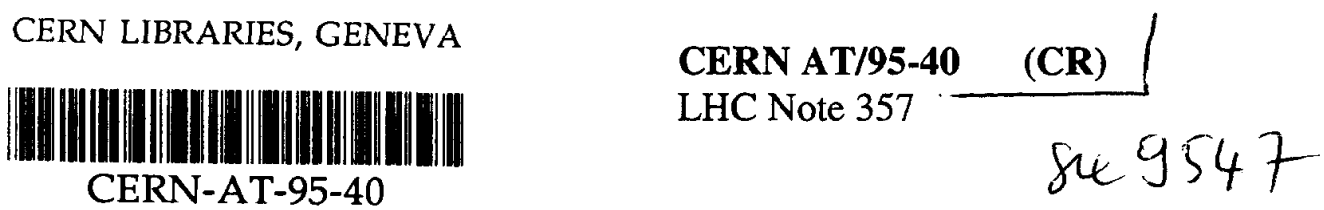

\title{
THE SUPERFLUID HELIUM CRYOGENIC SYSTEM FOR THE LHC TEST STRING: DESIGN, CONSTRUCTION AND FIRST OPERATION
}

\author{
A. Bézaguet, J. Casas-Cubillos, B. Flemsaeter, B. Gaillard-Grenadier, \\ Th. Goiffon, H. Guinaudeau, Ph. Lebrun, M. Marquet, \\ L. Serio, A. Suraci, L. Tavian and R. van Weelderen
}

\begin{abstract}
A major milestone in the preparation of the Large Hadron Collider (LHC) project is the testing and operation of a 50-m long superconducting magnet string, representing a half-cell of the machine lattice. This also corresponds to the length of the elementary cooling loops providing refrigeration at the $1.9 \mathrm{~K}, 4.5$-to- $20 \mathrm{~K}$, and 50 -to- $75 \mathrm{~K}$ levels to the LHC cryomagnets. Based on existing large-capacity cryogenic infrastructure, we have designed, built and are operating a dedicated cryogenic system feeding the LHC Test String, with installed capacities of $120 \mathrm{~W} @ 1.8 \mathrm{~K}$ and $10 \mathrm{~g} / \mathrm{s}$ supercritical helium at $4.5 \mathrm{~K}$. The system also includes $15 \mathrm{kA}, 1.6 \mathrm{kA}, 500 \mathrm{~A}, 250 \mathrm{~A}$ and 50 A current lead pairs for powering of main and auxiliary magnet circuits, as well as a $120 \mathrm{~kW}$ liquid nitrogen vaporizer for controlled cooldown of the $10^{5} \mathrm{~kg}$ cold mass. The system is fully instrumented, controlled by dedicated industrial PLCs connected to an industrial supervision system. We report on performance in operation, including response of the system to transients such as current ramp and discharge, as well as magnet resistive transitions.
\end{abstract}

\section{INTRODUCTION}

The Large Hadron Collider (LHC) project, approved by the CERN Council in December 1994, will be the next major research facility in high-energy physics. ${ }^{1}$ Based on a ring of high-field, twin-aperture superconducting magnets ${ }^{2}$ operating in superfluid helium below $2 \mathrm{~K},{ }^{3}$ to be installed in the $26.7 \mathrm{~km}$ circumference tunnel of the present LEP collider, it will provide proton-proton collisions with a center-of-mass energy of $14 \mathrm{TeV}$ and at an unprecedented luminosity of $1034 \mathrm{~cm}^{-2} \cdot \mathrm{s}^{-1}$. Therefore, the LHC also represents a major engineering challenge in applied superconductivity and cryogenics, ${ }^{4}$ and has thus required a specific $R \& D$ programme in these domains.

Cryogenic Engineering Conference and International Cryogenic Materials Conference, July 17-21 1995, Columbus - Ohio, USA 


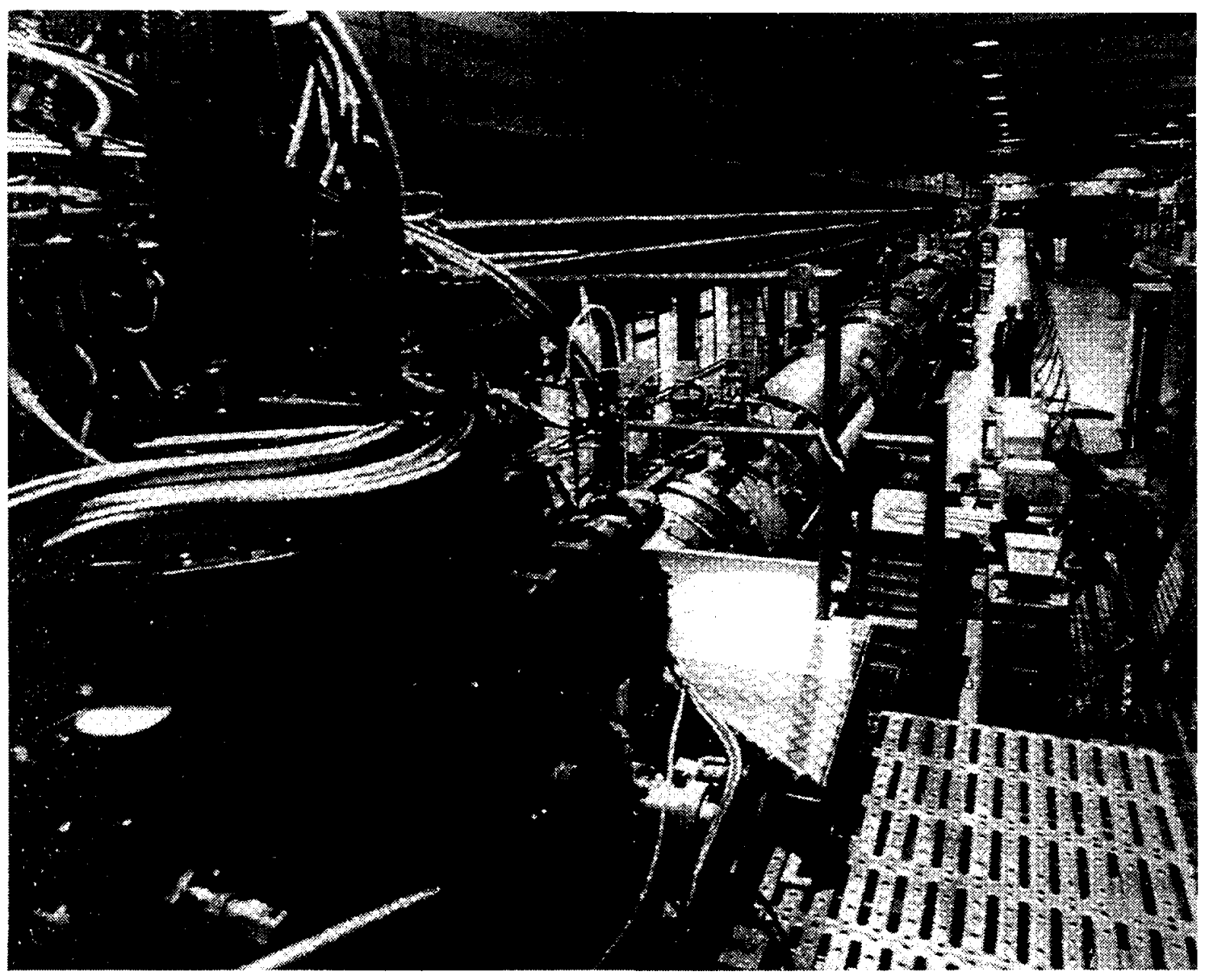

Figure 1. General view of LHC Test String

An important milestone in the validation of the basic technical choices, as far as main accelerator systems - magnets, cryogenics and vacuum - are concerned, is the testing and operation of a full-scale magnet string, representing a half-cell of the machine lattice. After recalling basic operating principles of test string cryogenics, we describe system layout, report on the spring 1995 campaign and present main results concerning cryogenics.

\section{PRINCIPLES OF OPERATION AND SYSTEM LAYOUT}

The first version of the LHC test string was assembled, commissioned and operated for the first time at the end of $1994 .^{5}$ Due to delays in the delivery of the $10 \mathrm{~m}$-long dipole prototypes, one quadrupole (Q) and only two dipoles (D1 and D2) were installed in the string, on a concrete beam with a slope of $1.4 \%$ (see figure 1), to exactly reproduce the extreme conditions that will be encountered in the LHC tunnel. Even though the results obtained with this configuration are sufficient to validate the basic technical choices, the other two dipoles will be installed as soon as they become available.

The principal components of the cryogenic system are the String Feed Box (SFB), the String Return Box (SRB), and the saturated superfluid helium circuit coupled to the pressurized (1 bar) superfluid helium bath through a corrugated heat exchanger tube. ${ }^{6.7}$ This acts as a linear cold source of large developed heat exchange area and at quasi-constant 
temperature, irrespective of the magnet position in the string. Furthermore, the high apparent thermal conductivity of superfluid helium, pressurized at 1 bar and permeating the superconducting windings thanks to its low viscosity, is exploited to transport the heat to the two-phase saturated helium II, flowing inside the heat exchanger tube.

The SFB external mechanical assembly, capable to withstand the pulling force of $8 \mathrm{t}$ during evacuation of the insulation vacuum, contains the main cryostat, used to distribute the liquid helium to different circuits in order to perform refrigeration and transient phases (i.e. cooldown and warm-up). This cryostat is equipped with several pairs of current leads for powering of dipole and quadrupole $(15 \mathrm{kA})$ and later correction elements $(50,250,500$ and $1600 \mathrm{~A}$ ). Furthermore, the SFB contains a gas counterflow heat exchanger, a liquid/gas heat exchanger, a very low pressure liquid subcooler, as well as all the valves and instrumentation necessary for the cryogenic operation of the string. The SRB is the end module of the string and is used to close the cryogenic loops as well as the insulation vacuum. The design of completely autonomous modules allowed the prior testing of the full cryogenic loop without magnet.

The cooling scheme is implemented in independent cooling loops, each extending over the total length of the string (figure 2). Liquid He I taken from the main cryostat is subcooled in a very low pressure heat exchanger and distributed through line $\mathrm{A}$, where it is expanded to saturation through a Joule-Thomson valve and fed to the far end of the heat exchanger tube. The low saturation pressure is maintained on the flowing two-phase helium by pumping the vapor through line $\mathrm{B}$ and the very low pressure heat exchanger. Line $\mathrm{C}$ supplies supercritical helium through the magnet supports to intercept residual conduction at $4.5 \mathrm{~K}$ and through the magnet cold mass to perform the operation of cooldown, filling and warming-up (in the latter case high pressure gaseous helium is used).

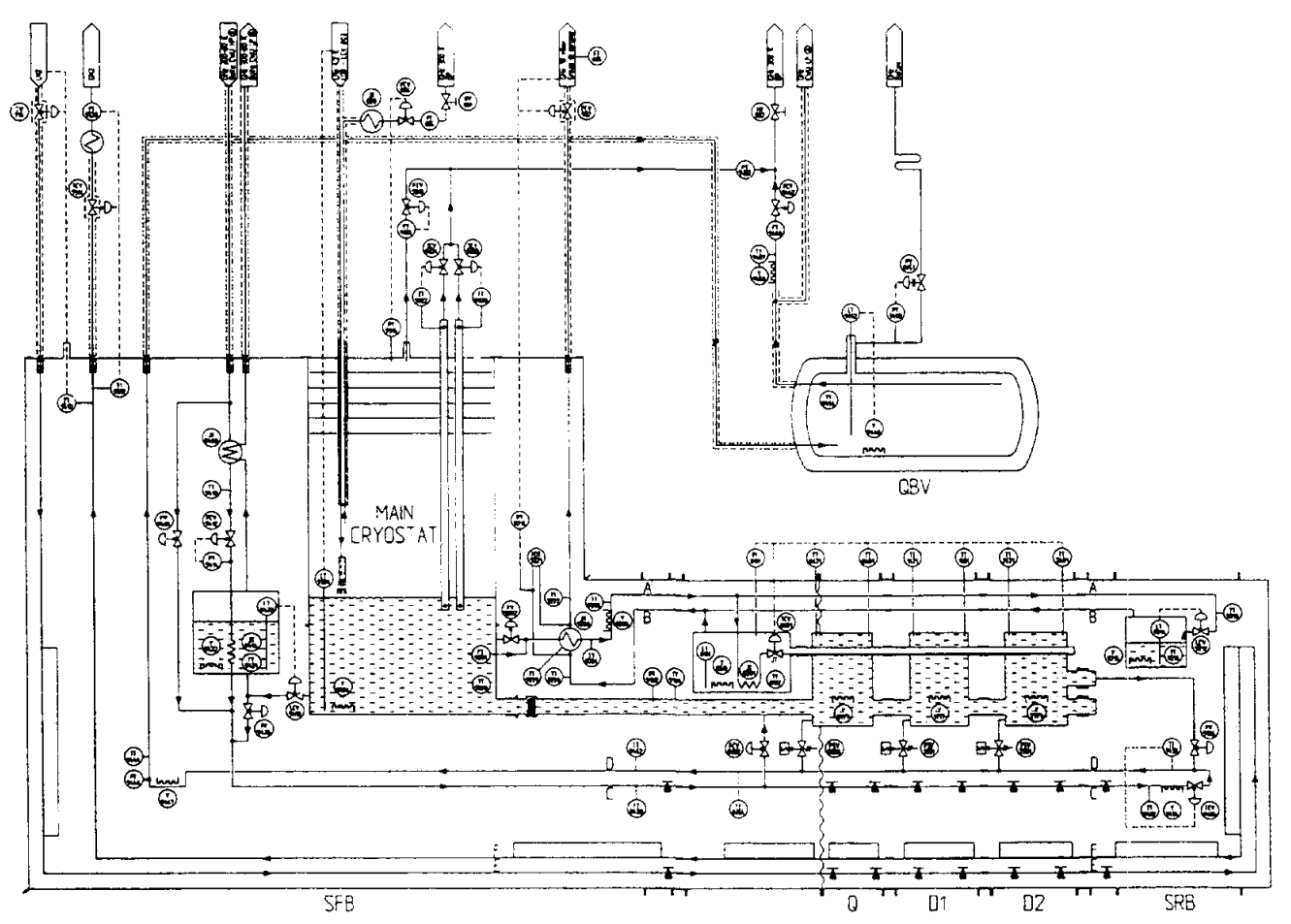

Figure 2. Cryogenic flow-scheme of LHC Test String (Phase 1) 
Line $\mathrm{E}$ and $\mathrm{F}$ are used to supply liquid nitrogen to the thermal shield and magnet support to intercept heat at the $90 \mathrm{~K}$ level.

Main features of the dipole cryostat $^{8}$ are the integration of all pipes distributing refrigeration, the support and positioning of the large cold mass by cylindrical post made of non-metallic composite materials and the use of multilayer reflective insulation.

The short straight section cryostat ${ }^{9}$ is based on the same design principle and houses the local cryogenic components of the superfluid cooling loop and an insulation vacuum barrier.

After a magnet resistive transition, ${ }^{10}$ the resulting pressure rise is contained below the $2 \mathrm{MPa}$ maximum design pressure of the cold mass by opening the quench relief valve ${ }^{11}$ on the quench trigger and discharging helium in line $\mathrm{D}$.

The system also makes full use of the pre-existing cryogenic infrastructure ${ }^{12}$ that comprises a $6 \mathrm{~kW}$ cryogenic plant capable of producing $18 \mathrm{~g} / \mathrm{s}$ of liquid helium, a Warm Pumping Unit (WPU) to pump on the saturated superfluid helium up to $6 \mathrm{~g} / \mathrm{s}$, a Quench Buffer Vessel (QBV) $(2000 \mathrm{~L})$ capable of recovering the total volume of liquid discharged from the magnets after a quench, the balloon system $\left(300 \mathrm{~m}^{3}\right)$ to recover the gaseous helium expelled after a quench and the Cooling and Warming-up Unit (CWU), which provides temperature-controlled gaseous helium in the range 300 to $80 \mathrm{~K}$, using a liquid nitrogen/gaseous helium heat exchanger and a $25 \mathrm{~kW}$ heater.

\section{INSTRUMENTATION AND PROCESS CONTROL}

The LHC test string is equipped with the following cryogenic instruments: temperature and pressure sensors, liquid level gauges and mass flowmeters. Of these only the liquid level gauges and platinum thermometers have a standard response curve and do not need to be calibrated individually.

To measure liquid helium mass flow in the superfluid helium cooling circuit a Venturi flowmeter ${ }^{13}$ at $4.5 \mathrm{~K}$ and a thermal flowmeter at $2.2 \mathrm{~K}$ are used. The thermal mass flowmeter confirmed the correct operation of the Venturi in spite of possible electromagnetic interference between cold pressure transducer and the main $12 \mathrm{kA}$ current bus feeding the superconducting magnets. Tests were also done to compare the two cryogenic flowmeters with ambient temperature differential pressure and thermal flowmeters at the outlet of the WPU.

Magnet temperature measurements are done in the $300 \mathrm{~K}$ to $1.6 \mathrm{~K}$ range by using a platinum and Allen-Bradley resistance thermometer pairs. The Allen-Bradley thermometers had to be recalibrated in situ because they presented temperature offsets that could be as high as $0.2 \mathrm{~K}$ while the magnets temperature needs to be regulated to within better than $0.05 \mathrm{~K}$ at an absolute temperature that could range between $1.8 \mathrm{~K}$ and $1.9 \mathrm{~K}$. This calibration was done for temperatures below $2 \mathrm{~K}$ to within better than $0.01 \mathrm{~K}$ thanks to the extremely good thermal conductance of pressurized superfluid liquid helium. The temperature reference was given by the pressure of the saturated liquid helium flowing inside the distributed heat exchanger. No effort was done to make in-situ temperature calibrations in normal liquid helium because of the difficulty to have an isothermal liquid helium I bath; furthermore the magnets are never operated in this temperature range.

The magnet pressure is measured by using piezoresistive cold sensors ${ }^{14}$ with a typical range from 0 to $3 \mathrm{MPa}$ and a response that strongly depends on the temperature. After the occurrence of a quench they all yielded a reading $60 \%$ below the one expected and this for a few tens of minutes. This effect, not completely understood, might be due to a sensor temperature higher than the one given by the thermometers installed in the magnets. 
The cryogenic process control is performed using an industrial Programmable Logic Controller (PLC) in which the number of $\mathrm{V} / \mathrm{O}$ channels is of the order of 250 and there are about 30 closed control loops. The automatic operation modes include the string cooldown, normal operation, quench recovery and warm-up. This equipment is interfaced with a supervision system provided by CERN's industrial control group. ${ }^{12}$

In addition, around 140 cryogenic transducers are recorded for analysis purposes by the data acquisition system with $1 \mathrm{kHz}$ capability.

\section{COOLDOWN AND WARMUP}

The string cooldown is started once the insulation vacuum is around $10^{-2} \mathrm{~Pa}$. The first phase from ambient to $80 \mathrm{~K}$ is achieved passing pressurized $\mathrm{GHe}$ from the CWU at progressively decreasing temperature, regulated on the overall string gradient in order to avoid thermal stresses on the magnets. In the two complete cooldown phases, the flow was set to $50 \mathrm{~g} / \mathrm{s}$ with $50 \mathrm{~K}$ and $60 \mathrm{~K}$ overall gradient respectively, with almost no difference in cooling speed (figure 3 [60 K gradient]). At the same time liquid nitrogen is sent and vaporized in the thermal shield. When the cold mass reaches $80 \mathrm{~K}$, the cooldown to $4.5 \mathrm{~K}$ can be done in two ways: one using liquid helium directly from the cryostat, the other using supercritical helium (figure 4). In the latter case, a $80 \mathrm{~K}$ GHe flow is provided by the CWU and subcooled through two heat exchangers down to [4.5 K, $2.5 \mathrm{bar}$ ] and then expanded through the feeding valve in the cold mass. At the end of this phase, the $700 \mathrm{~L}$ volume of the cold mass is filled up and the WPU pumping rate limits the cooling speed down to $1.9 \mathrm{~K}$ (figure 5). The gained operational experience has reduced the time of cooldown from $70 \mathrm{~K}$ to $4.5 \mathrm{~K}$ down to 9 hours using the LHe I version.

Warming-up is achieved by pressurized GHe at progressively increasing temperature flowing in the system from the CWU and regulated on the overall string gradient. Figure 6 shows a warm-up at $80 \mathrm{~g} / \mathrm{s}$ and with $60 \mathrm{~K}$ maximum overall gradient.

The results obtained, summarized in table 1, can be extrapolated to estimate the time required for cooling, warming and intervention on a full octant of the final LHC machine. The different cold/warm fronts show the good heat exchange capacity of the magnets and underline the limiting factors, i.e. maximum gradient on the magnets and cryogenic plant characteristics.

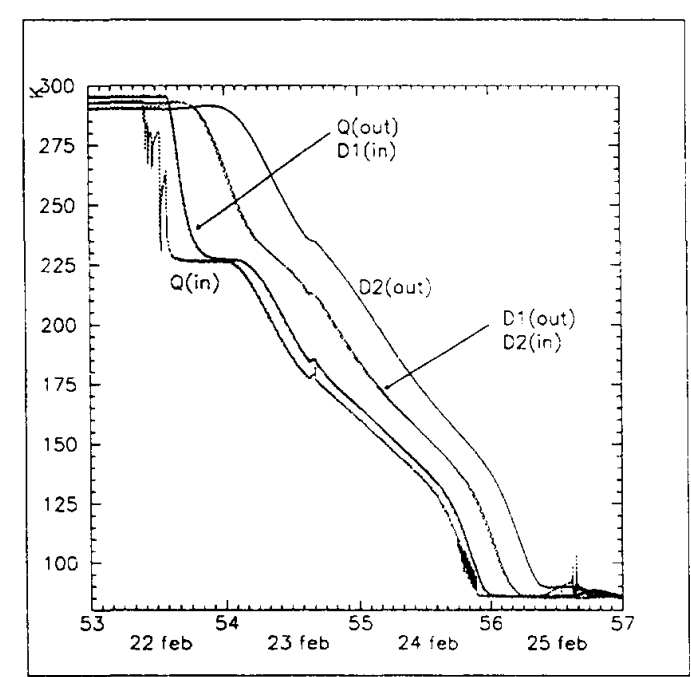

Figure 3. Forced-flow cooldown, $300-80 \mathrm{~K}$

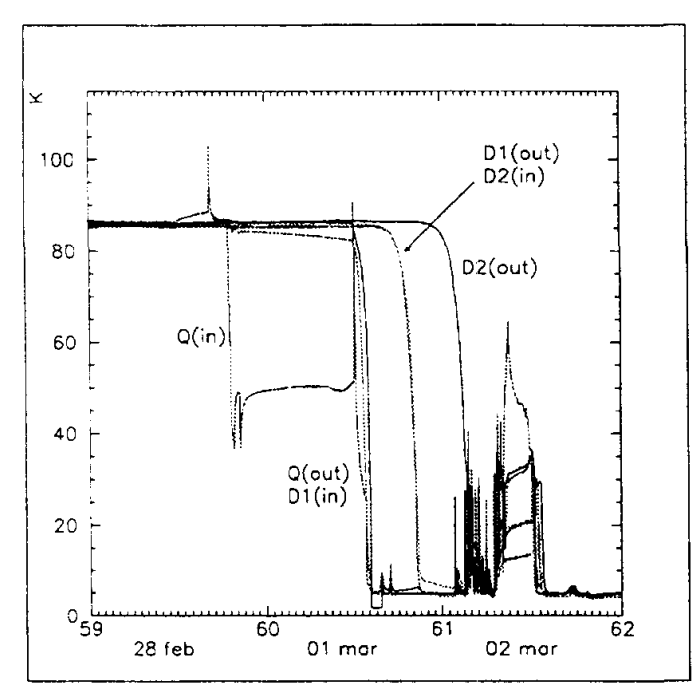

Figure 4. Supercritical helium cooldown, $80-4.5 \mathrm{~K}$ 


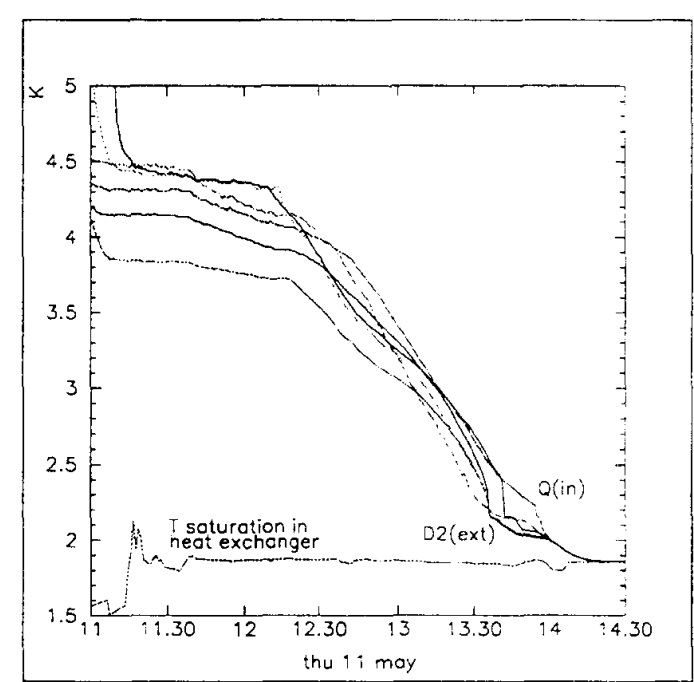

Figure 5. Final cooldown, 4.5-1.8 $\mathrm{K}$

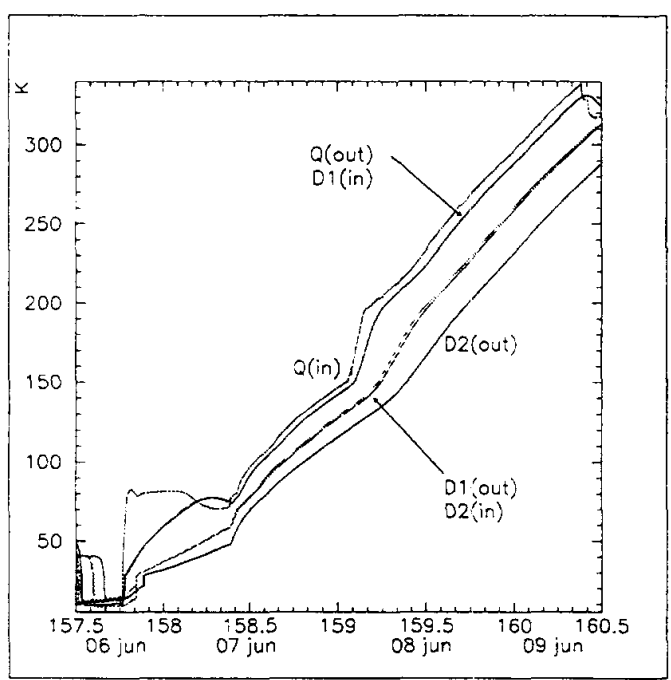

Figure 6. Warming-up

\section{STEADY OPERATION AND CURRENT RAMPS}

The superfluid helium cooling loop controls the temperature of the static pressurized helium II bath of the superconducting magnets by gradual vaporization of the flow of saturated helium II along the wetted length of the corrugated heat exchanger tube, fed by the Joule-Thomson valve. This process involves separated two-phase flow of helium II, transverse Kapitza and solid conductance across the tube wall as well as longitudinal conduction in pressurized helium II, and thus results in strongly non-linear behaviour.

Particular care and several simulation tests with applied heat loads were devoted to the optimization of the control law for the Joule-Thomson valve, in order to maintain the magnets at their operating temperature along the string length and throughout steady and transient operating modes. ${ }^{15}$ Heat loads up to $1 \mathrm{~W} / \mathrm{m}$ were applied on the cold mass to simulate a larger heating power than the one that will be deposited by the proton beams. The maximum temperature excursions registered were below $30 \mathrm{mK}$ and during nominal ramping rates (i.e. $10 \mathrm{~A} / \mathrm{s}$ ) the temperature increase was of the order of $6 \mathrm{mK}$ (figure 7).

Even with such a short response time, the system stability was not compromised and the temperature oscillations over a period of 48 hours were smaller than a few millikelvin.

Current discharge at nominal rate (around $130 \mathrm{~A} / \mathrm{s}$ ) resulted in a magnets temperatures increase of $50 \mathrm{mK}$, well below the transition temperature of $2.2 \mathrm{~K}$.

Table 1. Cryogenic system performance summary

\begin{tabular}{|c|c|c|}
\hline Phase & Time & Consumption \\
\hline 300 - 80 K Cold mass & 3.5 days & $\mathrm{GHe} \quad 50 \mathrm{~g} / \mathrm{s}$ \\
\hline Thermal shield & 2 days & $\mathrm{N} 2145 \mathrm{~L} / \mathrm{min}$ \\
\hline $80-4.5 \mathrm{~K}$ & & \\
\hline using LHe & $<3$ days & $\mathrm{LHe} \quad 5 \mathrm{~g} / \mathrm{s}+700 \mathrm{~L}$ \\
\hline using $\mathrm{SHe}$ & $<3$ days & $\mathrm{GHe} 20 \mathrm{~g} / \mathrm{s}+\mathrm{LHe} 2 \mathrm{~g} / \mathrm{s}$ \\
\hline $4.5-1.8 \mathrm{~K}$ & $2 \mathrm{~h} 30 \mathrm{~m}$ & LHe $10 \mathrm{~g} / \mathrm{s}$ \\
\hline Quench Recovery (35-1.8 K) & $5-6$ hours & LHe $10 \mathrm{~g} / \mathrm{s}+700 \mathrm{~L}$ \\
\hline $4.5-300 \mathrm{~K}$ & 3 days & $\mathrm{GHe} \quad 80 \mathrm{~g} / \mathrm{s}$ \\
\hline
\end{tabular}




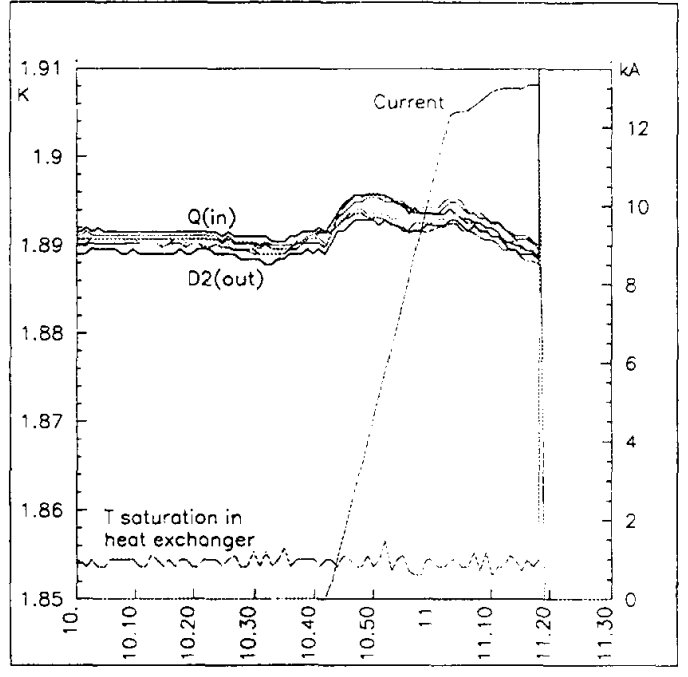

Figure 7. Stability of magnets temperatures along the string and response to current ramping

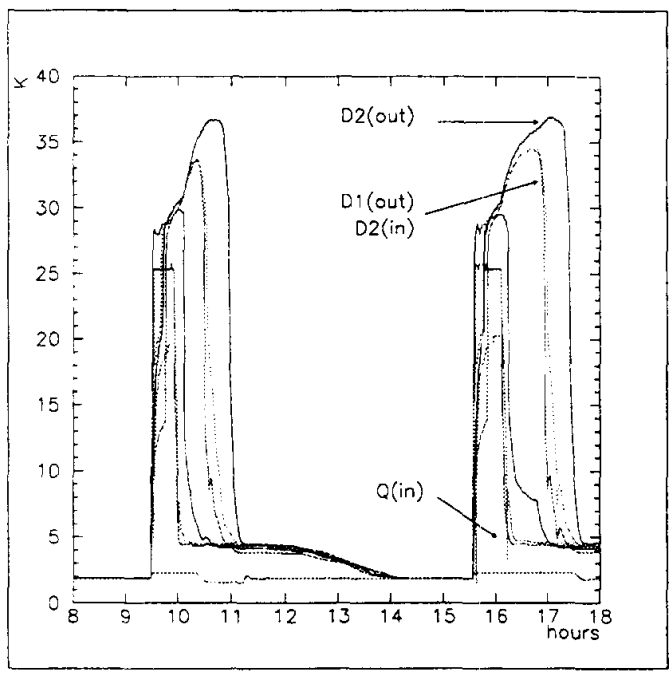

Figure 8. Recoveries after resistive transition

\section{MAGNET RESISTIVE TRANSITIONS AND RECOVERY}

One of the main goals of this campaign was the analysis of thermohydraulic effects of a resistive transition of a magnet (figure 8), when the energy stored in the coils (several MJ) is suddenly discharged in the liquid helium bath. Tests were performed mostly at a current of $13 \mathrm{kA}$ (corresponding to a field of $9 \mathrm{~T}$ ) varying mainly two parameters: the number of discharge valves used and the sequence of firing the magnet heaters. The ratio of liquid to gaseous helium recovered after being expelled from the cold mass through the discharge valves and the recovery line, respectively, in the QBV and in the balloons, was always of the order of 4 to 1 , while practically no liquid was left in the cold mass. Figures 9 and 10 show two typical pressure transients varying the number of discharge valves opened. The contained increase in peak pressure in the case of a single valve opening has justified increasing the spacing between these valves, thus gaining in cost and reliability.

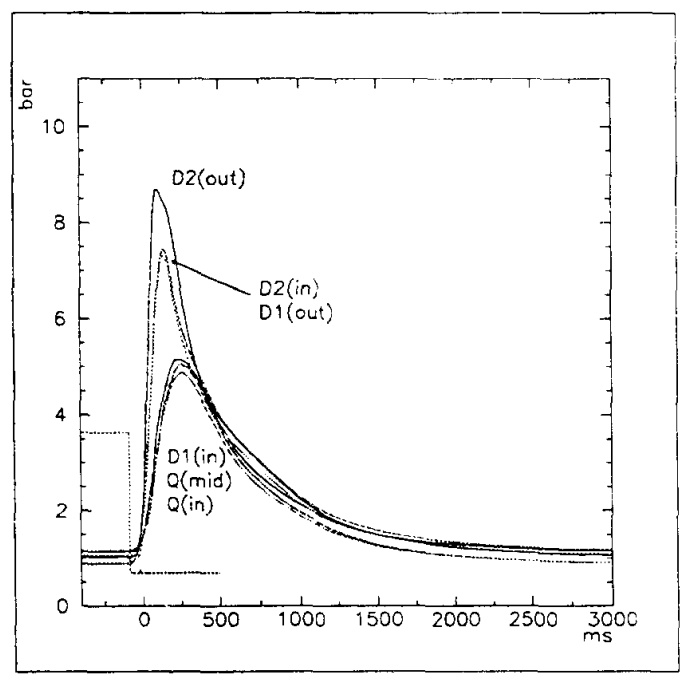

Figure 9. Thermohydraulic effects of a resistive transition with all discharge valves opened-12.8 kA

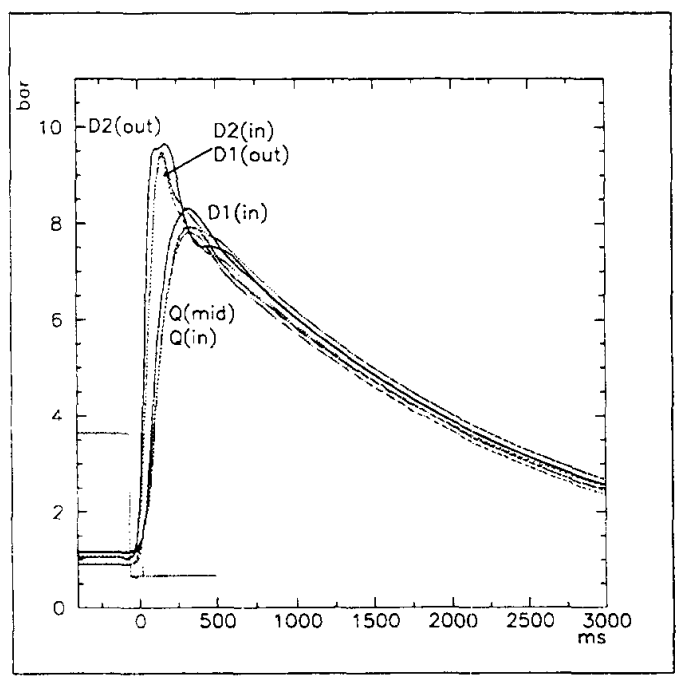

Figure 10. Thermohydraulic effects of a resistive transition with 2 discharge valves blocked-13.1 kA 


\section{CONCLUSIONS AND FUTURE OUTLOOK}

The first operation of the string was very successful and has validated the basic design choices of LHC cryogenics.

After a short summer shut-down, the string will be upgraded with a new dipole and the cryogenic system slightly modified to allow the verification of the performance of the superfluid helium cooling loop in counter-current two-phase flow. At the same time the control system strategies will be updated profiting from the operational experience gained. In line with the results obtained, only two discharge valves will be installed, one at each end of the string.

\section{ACKNOWLEDGEMENTS}

The authors wish to thank the LHC String Team for the valuable work performed in preparing and run the first experimental campaign of the string.

\section{REFERENCES}

1. L.R. Evans, "The Large Hadron Collider", invited paper at the Particle Accelerator Conference, Dallas (1995).

2. R. Perin for the LHC Magnet Team, "Status of LHC Programme and Magnet Development", invited paper at the Applied Superconductivity Conference, Boston (1994).

3. Ph. Lebrun, "Superfluid Helium Cryogenics for the Large Hadron Collider Project at CERN", Cryogenics 34 ICEC Supplement, pp.1-8 (1994).

4. L. Evans, "Advanced Technology Issues in the LHC Project", Proc. EPAC'94 Vol.1, World Scientific, pp. 429-433 (1994).

5. P. Faugeras, for the LHC String Team, "Assembly and Commissioning of the LHC Test String", paper presented at the Particle Accelerator Conference, Dallas (1995).

6. J. Casas-Cubillos, A. Cyvoct, Ph. Lebrun, M. Marquet, L. Tavian and R. van Weelderen, "Design Concept and First Experimental Validation of the Superfluid Helium System for the Large Hadron Collider Project at CERN", Cryogenics 32 ICEC Supplement, pp.118-121 (1992).

7. A. Bézaguet, J. Casas-Cubillos, Ph. Lebrun, M. Marquet, L. Tavian and R. van Weelderen, "The Superfluid Helium Model Cryoloop for the CERN Large Hadron Collider", Adv. Cryo. Eng. 39A, pp. 649. 656 (1994).

8. J.C. Brunet, J. Kerby, Ph. Lebrun, P. Rohmig, B. Szeless and L.R. Williams, "Design of LHC Prototype Dipole Cryostats", Cryogenics 32 ICEC Supplement, pp. 191-194 (1992).

9. W. Cameron, B. Jenny, G. Riddone, P. Rohmig and R. van Weelderen, "Design and Construction of a Prototype Superfluid Helium Cryostat for the Short Straight Sections of the CERN Large Hadron Collider", Adv. Cryo. Eng. 39A, pp. 663-670 (1994).

10. G. Gerin, B. Vullierme and R. van Weelderen, "Measurement of the Thermo-Hydraulic Behaviour of LHC Dipole Prototypes after Quench", paper presented at this conference.

11. H. Danielsson, G. Ferlin, B. Jenninger, C. Luguet, S.E. Milner and J.M. Rieubland, "Cryogenic Performance of a Superfluid Helium Relief Valve for the LHC Superconducting Magnets", paper presented at this conference.

12. V. Benda, G. Duraffour, A. Guiard-Marigny, Ph. Lebrun, F. Momal, R. Saban, V. Sergo, L. Tavian and B. Vullierme, "Cryogenic Infrastructure for the Superfluid Helium Testing of LHC Prototype Superconducting Magnets", Adv. Cryo. Eng., 39A pp. 641-648 (1994)

13. A. Rivetti, G. Martini and G. Birello, "Metrological Performances of Ventury Flowmeters in Normal, Supercritical and Superfluid Helium", Adv. Cryo. Eng., 39B p 1051-1058 (1994)

14. Siemens KPY

15. B. Flemsaeter, "Contribution to the Dynamic Analysis and Optimal Control of the Superfluid Helium Cooling Loop for the LHC Magnet String", Diploma Thesis, Norwegian Institute of Technology,

Trondheim (1995). 